\title{
Communication
}

\section{Unsteady-State Mathematical Modeling of Hydrocarbon Feedstock Pyrolysis}

\author{
Igor Dolganov, Ajur Bunaev and Irena Dolganova *(D)
}

School of Earth Sciences \& Engineering, National Research Tomsk Polytechnic University, 634050 Tomsk, Russia; dolganovim@tpu.ru (I.D.); aiurbunaev@gmail.com (A.B.)

* Correspondence: dolganovaio@tpu.ru

Received: 14 September 2020; Accepted: 30 October 2020; Published: 31 October 2020

check for updates

\begin{abstract}
Hydrocarbon feedstock pyrolysis is an important method for obtaining monomers that are then used to produce various polymer materials. During this process, a mixture of hydrocarbons is heated at a high temperature and in the absence of oxygen. Because of the side reactions of polymerization and polycondensation, coke products are formed and settle on the inner walls of the coil. This decreases the technical efficiency of the hydrocarbon pyrolysis furnace during its operation, making the process unsteady. In the present research, we developed an unsteady-state mathematical model of hydrocarbon feedstock pyrolysis in order to improve the monitoring, forecasting, and optimization of this technological process. This model can calculate the rate of coke deposition along the length of the coil, considering the technological parameters and the composition of the supplied raw materials (the calculated value of coke deposition rate equals $0.01 \mathrm{~mm} /$ day). It was shown that with an increase in the propane/butane ratio from $4 / 1$ to $1 / 4 \mathrm{~mol} / \mathrm{mol}$, the ethylene concentration decreases from $3.45 \mathrm{~mol} / \mathrm{L}$ to $3.35 \mathrm{~mol} / \mathrm{L}$.
\end{abstract}

Keywords: pyrolysis; hydrocarbon feedstock; unsteady-state; mathematical model

\section{Introduction}

Currently, almost all the objects that surround people and are used in everyday and professional activities are made from various polymer materials. Among these, the most common materials include polyethylene, polypropylene, polyvinyl chloride, polyethylene terephthalate, polystyrene, and many others. The substances used to produce these and many other polymers are the alkene monomers ethylene and propylene. Each of these alkene monomers has a single double bond that is responsible for their activity in polymerization reactions [1,2].

Thus, the high and unabated demand in the petroleum product market for ethylene and propylene obviously imposes rather stringent requirements not only on the quality of semi-finished products, but also, more importantly, on their quantity. This largely depends on the composition of the processed raw material, which, in turn, determines the optimal modes of the pyrolysis stage, which is the main method for obtaining the necessary monomers. During this process, a mixture of hydrocarbons is heated at a high temperature and in the absence of oxygen.

Today, one of the most common designs for the pyrolysis process is a tubular furnace. Devices of this type usually include two sections. The first one, located at the top of the apparatus, is convection. Here, the feedstock supplied to the apparatus is heated by the heat of the flue gases, evaporates, and is mixed with water vapor, also supplied to the apparatus, while being heating to the temperature at which the decomposition reaction will occur. The supplying of water vapor is necessary, since this makes it possible to reduce the rates of side reactions during pyrolysis. As a result, the partial pressure of hydrocarbons decreases and this facilitates the occurrence of reactions that increase the volume, that is, targeted primary reactions of hydrocarbons decomposition. The second, lower section is radiant. 
In this section, the heat generated by combustion in the fuel burners is already needed only to support the occurrence of hydrocarbon decomposition reactions. It should be noted that there are from two to eight coils inside the furnace in which these reactions take place.

The technical efficiency of the hydrocarbon pyrolysis furnace is determined both by the composition of the feedstock and by the thermodynamic parameters of the process. However, it inevitably decreases during the operation of the installation. This is due to formation of coke deposits during the pyrolysis process. These deposits are the result of the pyrolysis side reactions of polymerization and polycondensation, the products of which settle on the inner walls of the coil. This decreases the section's cross section and, in turn, increases in the pressure drop at the ends of the tube. As a result, the contact time increases, and the coke layer thickness becomes even thicker. In addition, coke deposits on the coil walls can create areas of thermal stress. This can lead to burnout, which is already an emergency situation that may require replacing of the entire coil.

According to the stated problems, hydrocarbons pyrolysis modeling is worth optimizing. There are two main directions of improving the high-temperature process of hydrocarbon feedstock pyrolysis. First is the modernization of the technology itself [3-9]. Within the framework of this direction, the burner devices are being modernized [10-13], research is being carried out to initiate the pyrolysis process, new and more efficient catalysts are being developed. The second direction is using the mathematical modeling method to search for optimal process modes. Both deterministic and stochastic models are developed and used [14-17]. A common feature of the problems solved in modeling the pyrolysis process is the constancy of the feed stock composition. However, in real conditions, especially in the case of supplying pyrolysis feedstock simultaneously from several enterprises, there are strong variations in the feedstock composition.

At present, there are a large number of studies of the pyrolysis process itself: the study of chemistry, kinetics, thermodynamic and hydrodynamic laws, and the development with further improvement of its mathematical models. Nevertheless, in these works, the processes of coke formation, its precipitation, and combustion are not considered. These processes narrow the performed developments and complicate the forecasting of the technological process. Having significant experience in unsteady processes modeling [18-21], we developed an unsteady-state mathematical model of hydrocarbon feedstock pyrolysis in order to improve monitoring, forecasting, and optimization of this technological process. As a base, we used the analysis of the hydrocarbon pyrolysis process and a previously proposed kinetics model, which is based on a somewhat simplified scheme of the process, allowing, nevertheless, for the calculation of concentrations of the main components of the reaction mixture for a wide range of process temperatures [17,22].

There are at least three main and significant problems that arise during development of mathematical models of technological processes. First, the volume of necessary calculations and processed information grows quickly, since determination of a large number of numerical values of the physicochemical parameters of a model is a nontrivial task. Second, the analysis of the results of calculations obtained using a mathematical model can be to a certain extent complicated by the large number of components of the reaction mixture, since, as a rule, the models do not consider their additional effects of interaction with each other. Thirdly, it is very difficult to compare the calculated data obtained using the mathematical model and the experimental data obtained from the existing production.

According to the information above, the aim of the study was to predict the operation of the pyrolysis unit, considering the changes in technological parameters, the composition of raw materials, and the amount of deposited coke.

To achieve this goal, it was necessary to perform a number of tasks:

(1) study the mechanism of the pyrolysis process itself and the mechanism of coke deposition;

(2) perform a thermodynamic analysis of the pyrolysis process;

(3) develop a formalized reaction network according to the known mechanism considering the thermodynamic analysis of the pyrolysis process; 
(4) develop a kinetic model of the pyrolysis process;

(5) develop an unsteady mathematical model of a pyrolysis reaction furnace with due consideration of the coke deposition on the inner surface of the coil;

(6) complement the system of equations with differential equations for changing the thickness of the coke layer and the pressure of the reaction medium along the length of the coil with the astronomical time;

(7) solve the inverse kinetic problem;

(8) verify the mathematical model;

(9) perform predictive calculations for the duration of the cycle of the pyrolysis furnace;

(10) perform optimization calculations to obtaining the maximum degree of conversion, selectivity, and duration of the cycle of the pyrolysis reaction furnace.

The novelty of this research lies in developing an unsteady mathematical model of the pyrolysis process. This model considers deposition of coke on the inner surface of the coil. The rate of coke deposition depends on the feedstock composition, on the temperature and pressure parameters, and on the mode of the medium movement in the apparatus. Such a model for the pyrolysis process has not been presented in the literature before.

\section{Materials and Methods}

In this research, the research object is the process of propane-butane fraction pyrolysis under the conditions of changing feedstock composition and thermodynamic conditions. The reaction network was developed based on the hydrocarbons reaction network that considers the following reaction occurrence:

$$
\begin{aligned}
& \mathrm{C}^{2} \mathrm{H}^{6} \rightarrow 0.47 \mathrm{C}_{2} \mathrm{H}_{4}+0.53 \mathrm{CH}_{4} \\
& \mathrm{C}_{3} \mathrm{H}_{8} \rightarrow 0.32 \mathrm{C}_{2} \mathrm{H}_{4}+0.34 \mathrm{C}_{2} \mathrm{H}_{6}+0.16 \mathrm{C}_{3} \mathrm{H}_{6}+0.18 \mathrm{CH}_{4} \\
& \mathrm{C}_{4} \mathrm{H}_{10} \rightarrow 0.10 \mathrm{C}_{4} \mathrm{H}_{6}+0.32 \mathrm{C}_{2} \mathrm{H}_{4}+0.27 \mathrm{C}_{3} \mathrm{H}_{6}+0.15 \mathrm{C}_{2} \mathrm{H}_{6}+0.16 \mathrm{CH}_{4} \\
& \mathrm{C}_{5} \mathrm{H}_{12} \rightarrow 0.16 \mathrm{C}_{3} \mathrm{H}_{6}+0.37 \mathrm{C}_{2} \mathrm{H}_{6}+0.35 \mathrm{C}_{2} \mathrm{H}_{4}+0.12 \mathrm{CH}_{4} \\
& \mathrm{C}_{2} \mathrm{H}_{4} \rightarrow 0.15 \mathrm{C}_{2} \mathrm{H}_{2}+0.85 \mathrm{H}_{2} \\
& \mathrm{C}_{2} \mathrm{H}_{4} \rightarrow \text { polymers } \\
& \mathrm{C}_{3} \mathrm{H}_{6} \rightarrow \text { polymers } \\
& \text { polymers } \rightarrow \text { coke }
\end{aligned}
$$

A mathematical model of the pyrolysis process is a system of exponential algebraic equations for calculating the rate constants of the corresponding reactions [17]:

$$
K_{i}=K_{0 i} \cdot P_{0} \cdot \exp \left(\frac{-E_{i}}{R T}\right), i \in\{1, \ldots, 7\}
$$

where $K_{i}$ is the rate constant of the $i$-th reaction, $\mathrm{s}^{-1} ; K_{0 i}$ is the preexponential coefficient, $\mathrm{s}^{-1} ; P_{0}$ is the pressure, atm.; $E_{i}$ is the activation energy of the $i$-th reaction, $\mathrm{J} / \mathrm{mol}$; and $T$ is the process temperature, $\mathrm{K}$.

The other 11 equations are differential. They describe the changes in the concentrations of each component of the hydrocarbon mixture during the pyrolysis process. The general view of the equation for each component is given below:

$$
\frac{d C_{k}}{d \tau}=\sum a_{i, j} \cdot K_{j} \cdot C_{i}
$$

where $C_{i}, C_{k}$ are the concentrations of $i$-th and $k$-th components, mol/L; $\tau$ is the contact time, $\mathrm{s}$; and $a_{i, j}$ is the stoichiometric coefficient of the $i$-th component in the $j$-th reaction.

The obtained system of differential and exponential equations is solved by the first order Runge-Kutta method. 
The coke concentration is calculated as:

$$
\frac{d C_{12}}{d \tau}=K_{8} C_{12}-\exp \left(0.023 \cdot C_{12}-1\right) \cdot G^{0.8} \cdot(D-2 \cdot \delta)^{-1.8}
$$

where $G$ is the feedstock flowrate, $\mathrm{kg} / \mathrm{s} ; D$ is the diameter of the tube, $\mathrm{mm}$; and $\delta$ is the coke layer thickness, $\mathrm{mm}$.

Due to the fact that the main goal of this work was to use the obtained mathematical model for regulating the operating mode of the furnace and optimizing the process with constantly changing feedstock composition, the process was assumed to be isothermal in order to increase the calculations speed.

The input data used to perform the calculations on the model are presented below.

According to the data provided by one of the petrochemical plants in Russia, the pressure drop between the two ends of the pyrolysis coil, with the maximum possible thickness of the coke layer before an emergency stop, is $0.265 \mathrm{MPa}$.

Thus, we can say that the difference is caused by the pressure loss due to friction against the coil walls and the coke layer along its length:

$$
\Delta P=\lambda \frac{L}{d_{e}} \cdot \frac{\omega^{2} \rho}{2}=0.265 \mathrm{MPa}
$$

where $\Delta P$ is the pressure drop, $\mathrm{MPa} ; \lambda$ is the friction loss coefficient along the length; $L$ is the coil length, $\mathrm{m} ; d_{e}$ is the effective diameter of the coil, $\mathrm{m} ; \omega$ is the flow rate of the hydrocarbon mixture, $\mathrm{m} / \mathrm{s}$; and $\rho$ is the density of the mixture, $\mathrm{kg} / \mathrm{m}^{3}$.

According to the technical data provided by the same plant, the heat exchange area is $176 \mathrm{~m}^{2}$. However, this is the total value for four parallel coils, so with a coil inner diameter of $100 \mathrm{~mm}$ :

$$
L=\frac{S_{\text {heat }}}{\pi d}=\frac{\left(\frac{176}{4}\right)}{\pi \cdot 0.1}=140.13 \mathrm{~m}
$$

where $S_{\text {heat }}$ is the heat exchange area, $\mathrm{m}^{2}$; and $\mathrm{d}$ is the coil inner diameter, $\mathrm{m}$.

Whereas the cross-stional area of the coil is:

$$
S_{\text {crossection }}=\frac{\pi d^{2}}{4}=\frac{\pi \cdot 0.1^{2}}{4}=0.00785 \mathrm{~m}^{2}
$$

The density in this case was calculated using the transformation of the Mendeleev-Clapeyron equation. In this case, the arithmetic mean pressure of the flow at the inlet and outlet of the coil was taken as the pressure:

$$
P=\frac{p \cdot M_{a v g}}{R T}=\frac{0.36 \cdot 10^{6} \cdot 52.4 \cdot 10^{-3}}{8.314 \cdot 1098}=2.066 \mathrm{~kg} / \mathrm{m}^{3}
$$

where $P$ is the pressure, $\mathrm{Pa}$; Mavg is the average molecular weight of the mixture, $\mathrm{kg} / \mathrm{mol}$; and $\mathrm{T}$ is the process temperature, $\mathrm{K}$.

Now it becomes possible to calculate the flow rate:

$$
\omega=\frac{G}{S_{\text {crossection }} \cdot \rho \cdot 3600}=\frac{4400}{0.00785 \cdot 2.066 \cdot 3600}=75.35 \mathrm{~m} / \mathrm{s}
$$

where $G$ is the mass flow rate, $\mathrm{kg} / \mathrm{h}$.

Thus, the effective diameter is calculated as:

$$
d_{e}=\lambda \frac{L}{\Delta p} \cdot \frac{\omega^{2} \rho}{2}=0.03209 \cdot \frac{140.13}{0.27 \cdot 10^{6}} \cdot \frac{75.35^{2} \cdot 2.066}{2}=0.09741 \mathrm{~m}=99.52 \mathrm{~mm}
$$


From here the thickness of the coke deposits can be calculated as:

$$
\delta=\left(d-d \_e\right) / 2=(100-99.52) / 2=0.48 \mathrm{~mm}
$$

where $\delta$ is the thickness of coke deposits, $\mathrm{mm}$.

Then, the deposition rate during the working cycle between the coke burning stops will be:

$$
\delta / t=\frac{1.156}{42}=0.0114 \mathrm{~mm} / \text { day }
$$

\section{Results and Discussion}

As part of the work presented in this article, a mathematical model of the reactor was adopted [17]. The adequacy of the adopted model without considering the coke formation was presented by the authors and showed an error of $0.4-0.7 \mathrm{wt} \%$. In the present research, the model was supplemented with equations for formation of polymers and coke, as well as the equations for the rate of coke deposition on the inner surface of the coil. According to the pyrolysis unit at one of the Russian enterprises, the pressure drop in the coil, at which the coke is burned out, is $0.265 \mathrm{MPa}$. For the given technological parameters, such a pressure drop can be obtained with an average coke layer thickness of about $1 \mathrm{~mm}$ (due to an increase in hydraulic resistance in the converging stion of the coil). The average duration of the cycle of the pyrolysis furnace between burns is $1000 \mathrm{~h}$. Thus, the approximate coke deposition rate is $0.0114 \mathrm{~mm} /$ day. However, it should be emphasized that this value is an average value over the entire operating cycle.

To verify the model, it is necessary to compare the model-calculated rate of coke deposition in the coil with that calculated from the pressure drop (Equations (4)-(11)) and according to the coke burnout data (Equations (12)-(17)). In this work, it was assumed that the main component of coke is coronene, so that the coke burning corresponds to the following reaction:

$$
\mathrm{C}_{24} \mathrm{H}_{12}+27 \mathrm{O}_{2}=24 \mathrm{CO}_{2}+6 \mathrm{H}_{2} \mathrm{O}
$$

To burn coke from pyrolysis coil furnaces, the technical air is supplied, and its flow rate varies during the process, as shown in Table 1.

Table 1. Air flowrate change for coke burning.

\begin{tabular}{cc}
\hline Duration, Hours & Air Flowrate, $\mathbf{k g} / \mathbf{h}$ \\
\hline 9.25 & 50 \\
0.5 & 100 \\
0.25 & 150 \\
0.25 & 200 \\
0.25 & 250 \\
0.875 & 315 \\
5.75 & 100 \\
5.25 & 315 \\
3.625 & 90 \\
Total air supply for burning, $\mathrm{kg}$ & 3493.125 \\
\hline
\end{tabular}

It should be noted that technical air with an oxygen content of $1.5 \mathrm{wt} \%$ is supplied. Thus, the mass of oxygen involved in the burning reaction is:

$$
m_{o_{2}}=\omega_{o_{2}} \cdot m_{\text {air }}=0.015 \cdot 3494.125=87.33 \mathrm{~kg}
$$

This corresponds to

$$
v_{o_{2}}=\frac{m_{o_{2}}}{M_{o_{2}}}=\frac{87.33}{32}=2.73 \mathrm{kmole}
$$


This means, according to the ratio, there is $0.1 \mathrm{kmol}$ in the coke reaction. Accordingly, the mass of coke deposited during the inter-regeneration cycle is:

$$
m_{\text {coke }}=M_{\text {coke }} \cdot v_{\text {coke }}=300 \cdot 0.1=30.32 \mathrm{~kg}
$$

With a coke density of $1493 \mathrm{~kg} / \mathrm{m}^{3}$, the volume of deposits is:

$$
V_{\text {coke }}=\frac{m_{\text {coke }}}{\rho_{\text {coke }}}=\frac{30.32}{1493}=0.2 \mathrm{~m}^{3}
$$

Then, with a pyrolysis coil length of $140 \mathrm{~m}$ and diameter of $100 \mathrm{~mm}$, the thickness of coke deposits accumulated during the inter-regeneration cycle is:

$$
\delta=\frac{d-\sqrt{d^{2}-\frac{4 V_{\text {coke }}}{L \cdot \pi}}}{2}=\frac{0.1-\sqrt{0.1^{2}-\frac{4 \cdot 0.2}{\pi \cdot 140}}}{2}=0.00046 \mathrm{~m}=0.46 \mathrm{~mm}
$$

Thus, the rate of coke deposition over 42 days is:

$$
\frac{\delta}{t}=\frac{0.46}{42}=0.0109 \mathrm{~mm} / \text { day }
$$

Figure 1 compares the model-calculated rate of coke deposition in the coil with that calculated from the pressure drop (Equations (4)-(11)) and according on the coke burnout data.

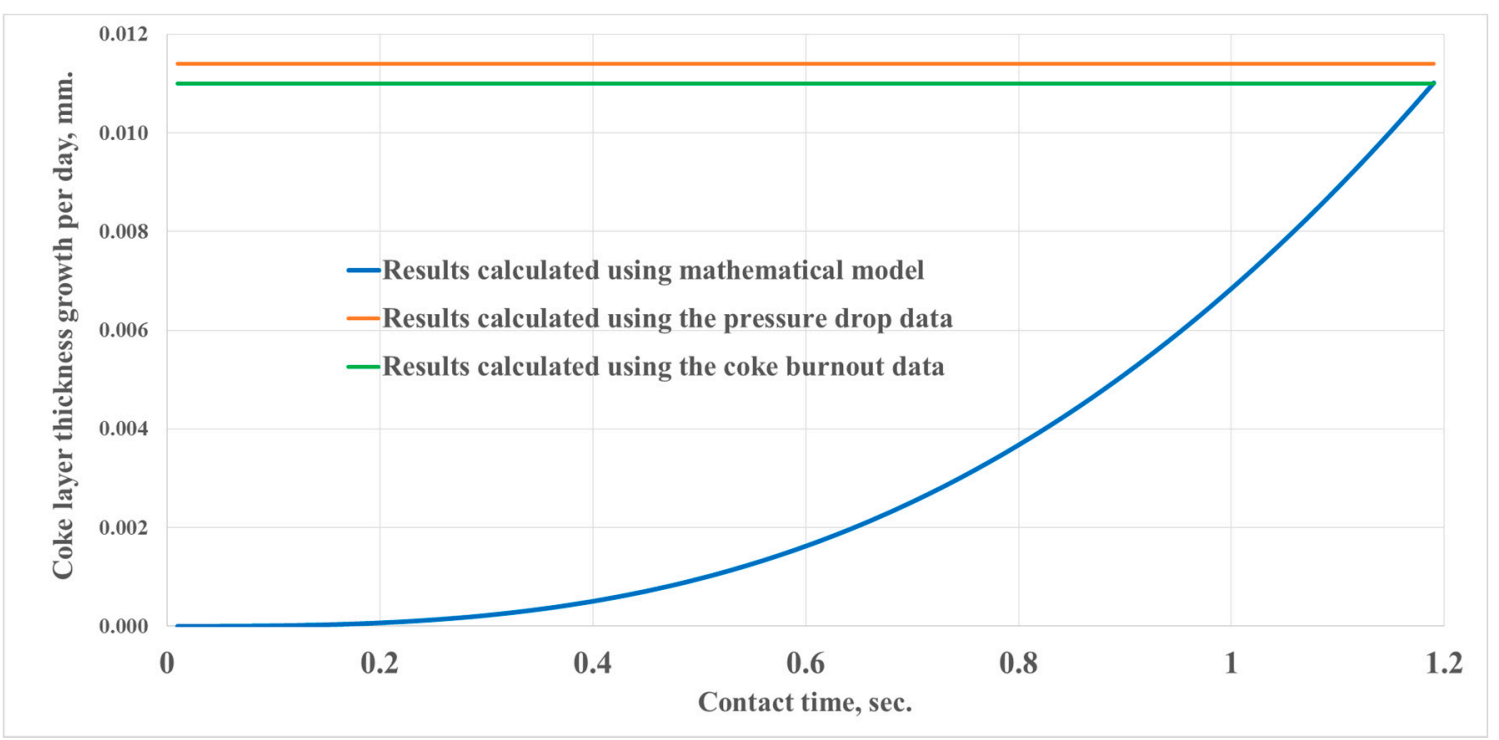

Figure 1. Thickness of coke layer accumulated each day depending on the contact time (coil length).

Figure 1 shows graphs of the coke layer thickness for one day along the length of the pyrolysis furnace coil, expressed by the contact time. The data on the coke layer thickness were calculated by three methods: using the considered model, using calculation methods through an assessment of the pressure loss, and also using the experimental data on the technical air supplied for coke burning. In this case, it is impossible to establish the distribution of thickness along the length of the coil in the last two ways, therefore, they are presented in the form of straight lines.

In general, from the results obtained, we can conclude that the model describes this process quite accurately for the first approximation.

The other way to assess the mathematical model reliability is to compare the calculated amount of coke accumulated in the coil during the whole cycle (42 days) with that calculated using the industrial 
data on coke burnout. The weight of coke determined using the experimental data was $30.32 \mathrm{~kg}$ (Equation (14)). The model calculation results are presented in Figure 2.

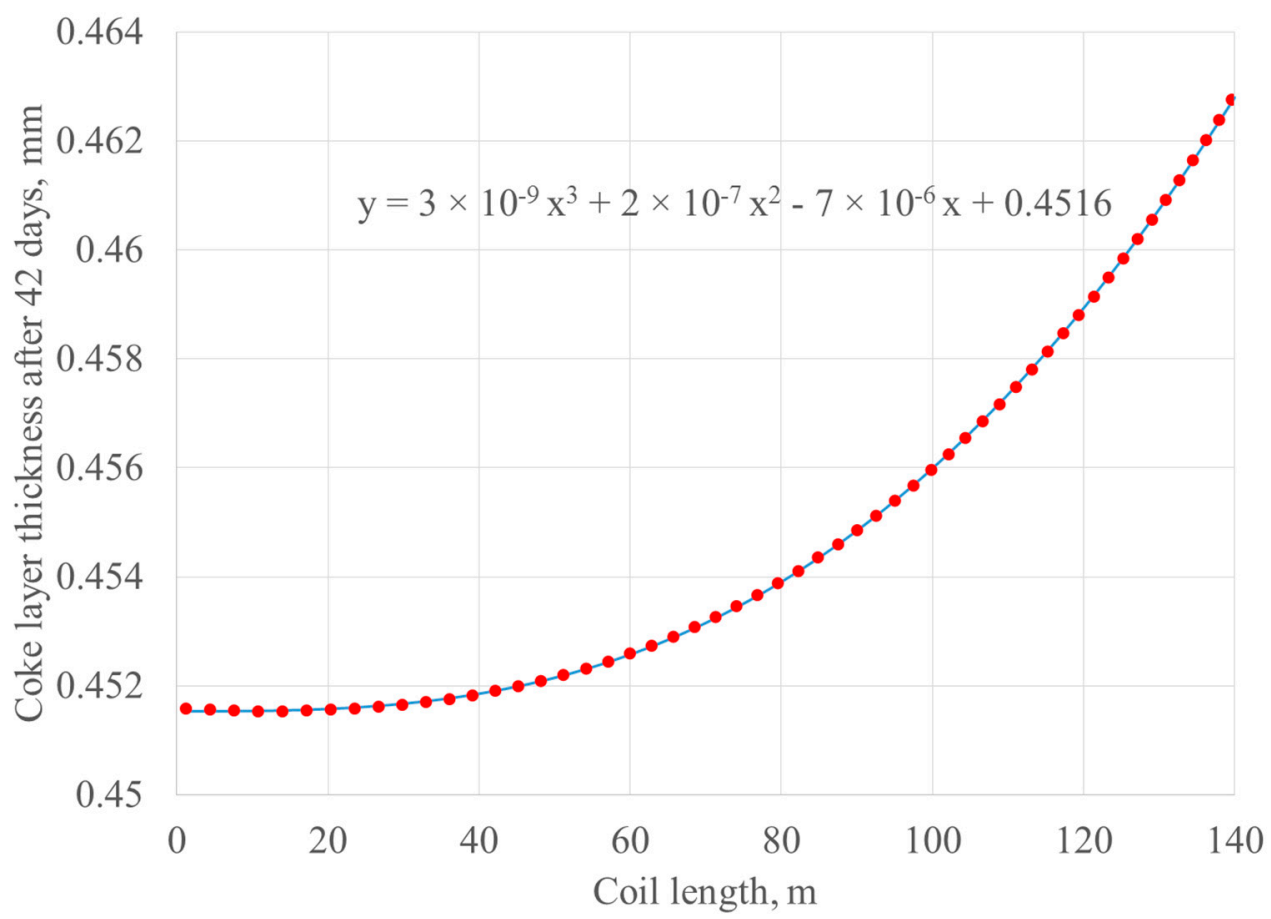

Figure 2. Coke layer thickness depending on the coil length at the end of the pyrolysis furnace coil.

Figure 2 can be used to calculate the mass of coke formed during the inter-regeneration cycle, which lasts 42 days. For this, a function was derived that describes the distribution of coke along the length of the coil. The volume of coke in the coil can be calculated as:

$$
\begin{gathered}
=\int_{0}^{L} \frac{\delta(l)}{1000} \cdot \pi \cdot D d l \\
=\int_{0}^{140} \frac{\left(3 \cdot 10^{-9} l^{3}+2 \cdot 10^{-7} l^{2}-7 \cdot 10^{-6} l+0.4615\right)}{1000} \cdot \pi \cdot 0.1 d l \\
=\left(3 \cdot 10^{-9} \frac{140^{4}}{4}+2 \cdot 10^{-7} \frac{140^{3}}{3}-7 \cdot 10^{-6} \frac{140^{2}}{2}+0.4516 l\right) / 1000 \cdot \pi \cdot 0.1 \\
=\frac{63.76}{1000} \cdot \pi \cdot 0.1=0.02002 \mathrm{~m}^{3}
\end{gathered}
$$

Accordingly, with a coke density of $1493 \mathrm{~kg} / \mathrm{m}^{3}$, the weight of coke accumulated over 42 days is:

$$
m_{\text {coke }}=\rho_{\text {coke }} \cdot V_{\text {coke }}=1493 \cdot 0.02002=29.89 \mathrm{~kg}
$$

\begin{tabular}{|c|c|c|c|c|c|c|c|}
\hline \multicolumn{7}{|c|}{ Hydrocarbon Feedstock Composition, wt $\%$} & \multirow{2}{*}{ Temperature, ${ }^{\circ} \mathrm{K}$} \\
\hline Methane & Ethane & Ethylene & Propane & Propylene & Butane & Butylene & \\
\hline 10.1 & 9.6 & 17.2 & 18.2 & 11.5 & 30.4 & 3 & 825 \\
\hline
\end{tabular}

This is in a good agreement with value of $30.32 \mathrm{~kg}$ calculated using the experimental data. The developed pyrolysis model was tested using the set of input data presented in Table 2.

Table 2. Model input data on propane-butane fraction.

The calculation results are presented in Figure 3. 


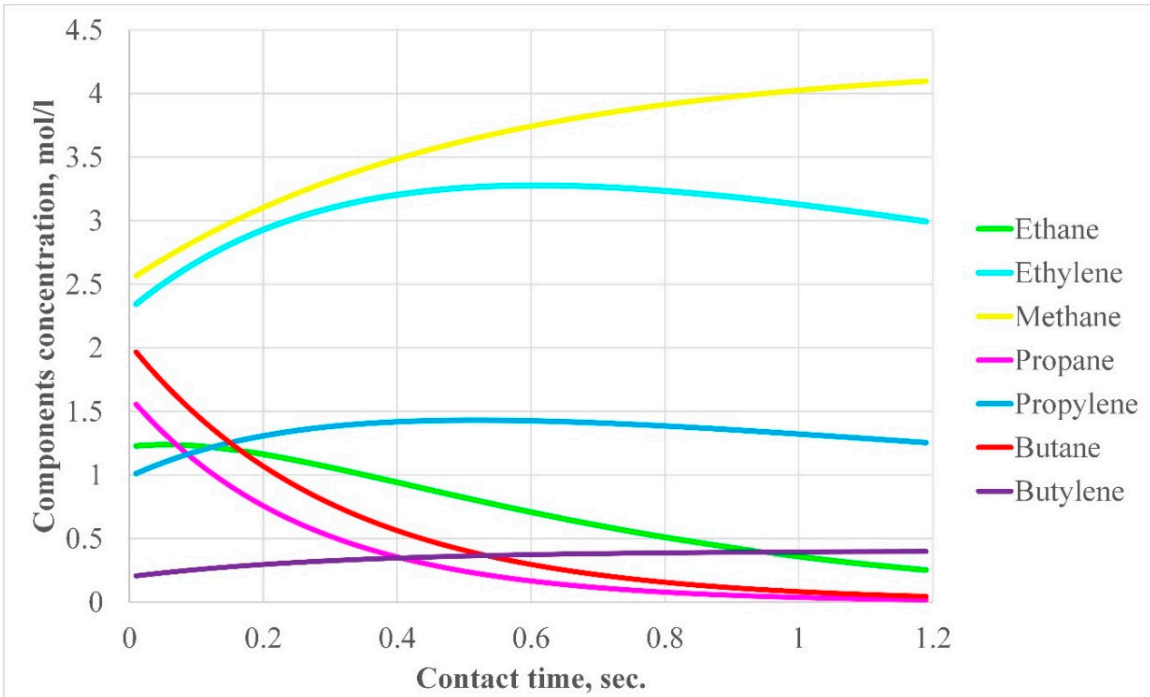

Figure 3. Change in the concentration of the components during the process.

Thus, it can be seen that there is an increase in the concentrations of ethylene and propylene initially, since the high-rate target reactions prevail. This is explained by the fact that the rates of side reactions depend on the concentration of the target products and increase as the target products accumulate. Consequently, side reactions, the formation of polymers and coke, begin to increase towards the end of the length of the pyrolysis furnace coil. As it can be seen in the list of reactions above, the reactants for these reactions are ethylene and propylene, i.e., they are intermediates. Therefore, approximately $0.5 \mathrm{~s}$ after the start of the process, a decrease in the concentration of the target components is observed.

Despite the astronomical time course incorporated in the model, no changes will occur in the dynamics of change in the hydrocarbons' concentration at any time. This is because the only component of this system that changes its value is the thickness of the coke layer. From this point of view, at this stage of the work, it would be more correct to call the model pseudo-steady. Nevertheless, it should be noted that in future work there is a plan to create a mechanism for changing the concentrations of all the components in real time, as well as to create a functional for predicting the state of the system, based on the data accumulated during the installation operation.

Figure 4 shows the dynamics of the coke layer growth inside the coil of the pyrolysis furnace during a short period.

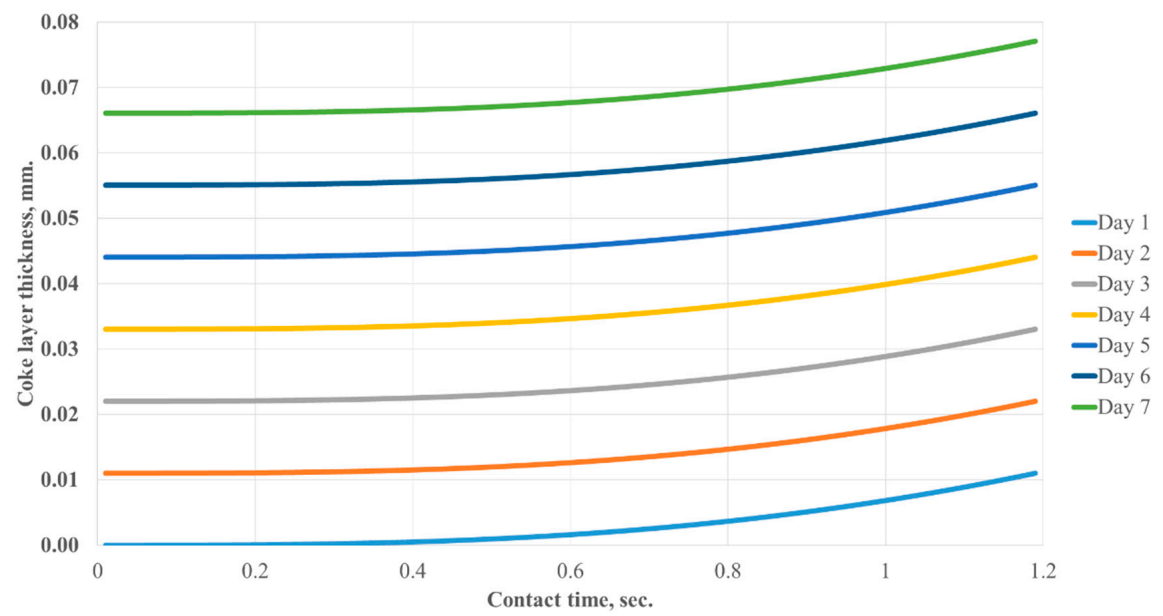

Figure 4. Change of the coke layer thickness. 
As presented in Figure 4, the thickness of the coke deposits grows evenly at the beginning of the coil and increases sharply towards the end of the coil through a contact time of $0.4-0.5 \mathrm{~s}$. This happens for the reasons described above, i.e., due to the intensification of side reactions yielding coke. The coke deposition rate in this example is quite high, $0.01 \mathrm{~mm}$ per day at its highest point. However, the growth profile is the same every day, whereas in reality the distribution of coke thickness along the pipe is more uneven. The model makes it possible to consider changes in the raw materials composition and technological modes when calculating the rate of formation and deposition of coke.

A slightly different situation is observed if the contact time is reduced (Figure 5).

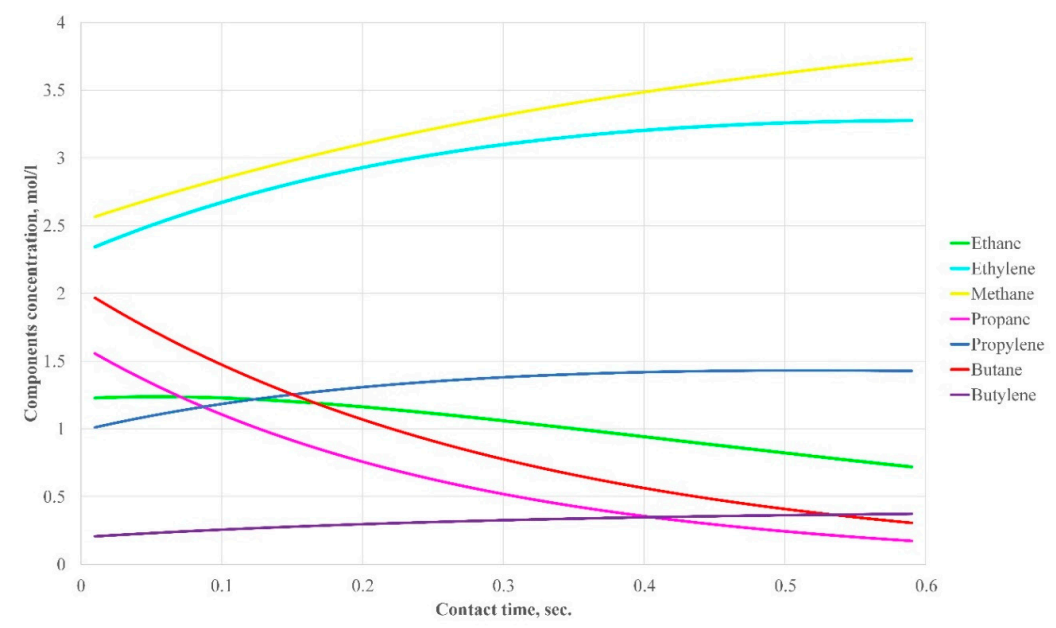

Figure 5. Changes in the concentrations of the components with a reduced contact time.

As can be seen from this graph, the concentrations of ethylene and propylene in this case increase during the entire process time, reaching a certain asymptote, in contrast to the previous case, when both values, reaching some maximum, decreased by the end of the process. Thus, one can suggest that within a reduced contact time period, neither ethylene nor propylene is able to form a significant amount of coke to deposit.

Figure 6 shows the dynamics of coke deposition under such conditions. As it can be seen, the absolute value of the coke layer thickness is obviously less, being only about $0.003 \mathrm{~mm}$ per day. On the other hand, its growth rate slightly increases: The thickness of deposition begins to grow rapidly $0.2 \mathrm{~s}$ into process. Thus, the steadiness in the concentrations of ethylene and propylene is explained, and some amount of these alkenes converts into the coke, but the amount of formed alkenes and that converted to coke per time unit are approximately equal.

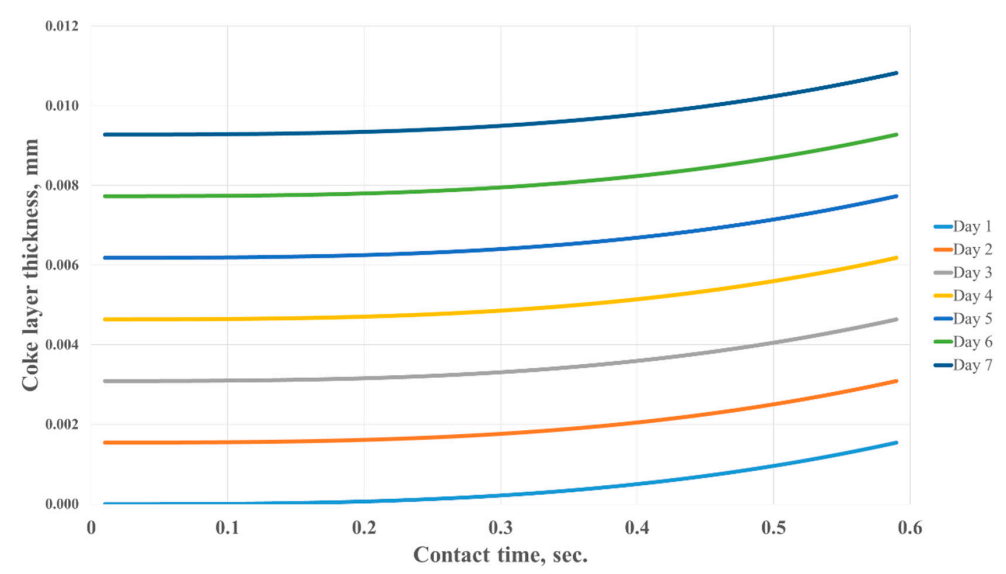

Figure 6. Change of the coke layer thickness with a reduced contact time. 
However, the distribution of deposits along the length of the coil remains the same. This is due to the very same reasons mentioned above in the paragraph concerning coke deposition with longer contact time. If the contact time is increased, the following situation is observed (Figure 7).

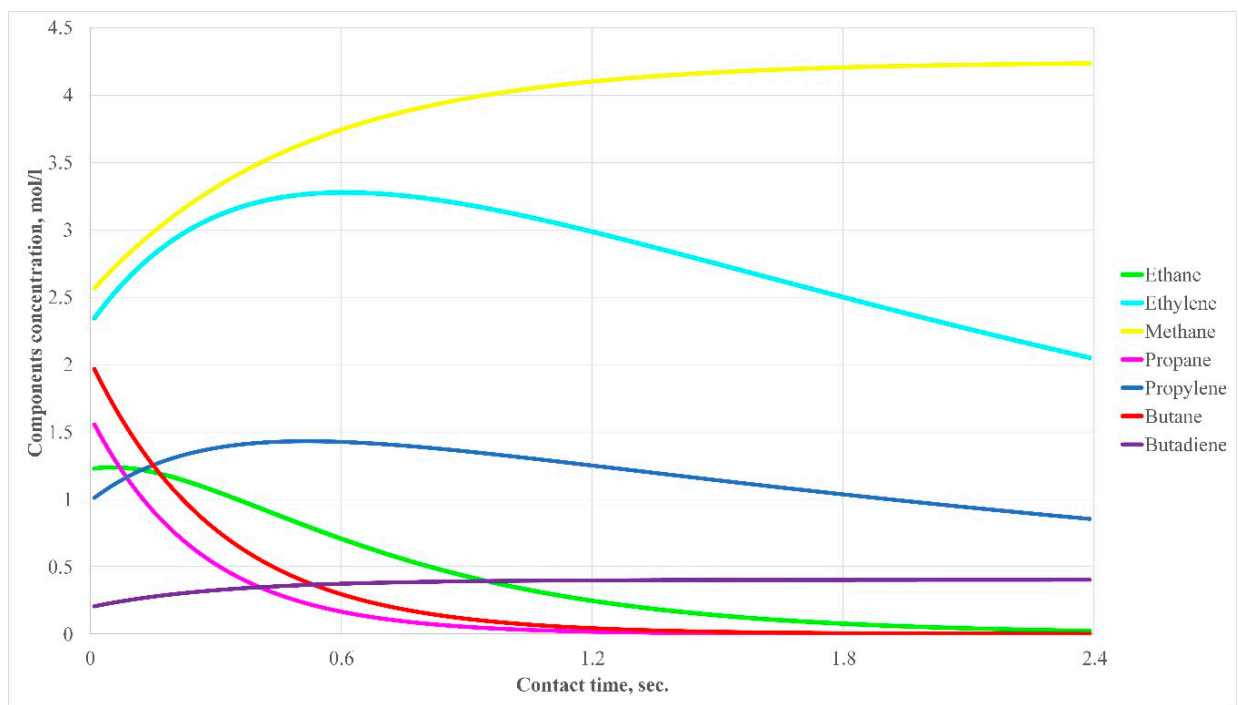

Figure 7. Change in the concentration of components with an increased contact time.

In this case, the concentration peak of the target components is shifted to the beginning of the coil, while the output concentration is the lowest of the three considered cases. Thus, it makes these conditions the worst of the three. It can be assumed that the hydrocarbon mixture stays too long in the reactor, so side processes, the very same as described for the simulation with $1.2 \mathrm{~s}$ contact time, increase their rate and intensity so much so that the output concentrations of target alkenes are lower than in the feed.

The growth of the coke layer thickness, in this case, shows opposite dynamics to that of the previous one. That is, with an increased contact time, the absolute value of the coke layer thickness is the largest in comparison with that of the previous examples, being about $0.07 \mathrm{~mm}$ per day. However, the point of coke deposition rapid growth shifted slightly towards the end, at $0.6 \mathrm{~s}$ into the process. (Figure 8).

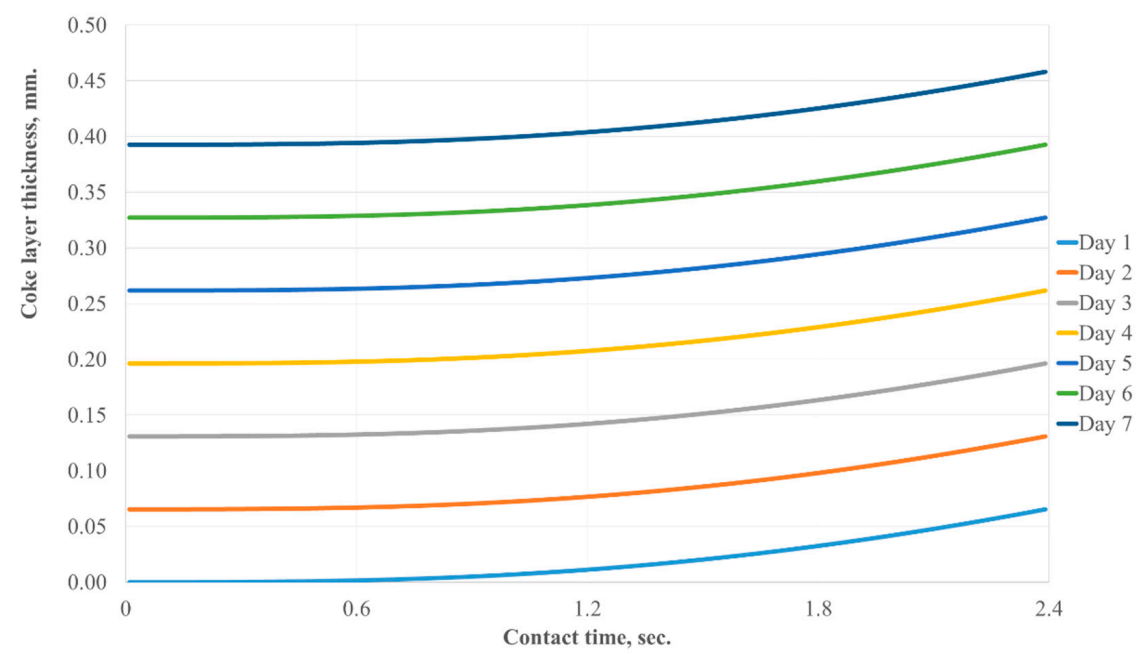

Figure 8. Change of the coke layer thickness with an increased contact time. 
In addition, a study was also performed on the effect of the propane/butane ratio in the feedstock on the yield of propylene and ethylene. The results are presented in Figure 9.

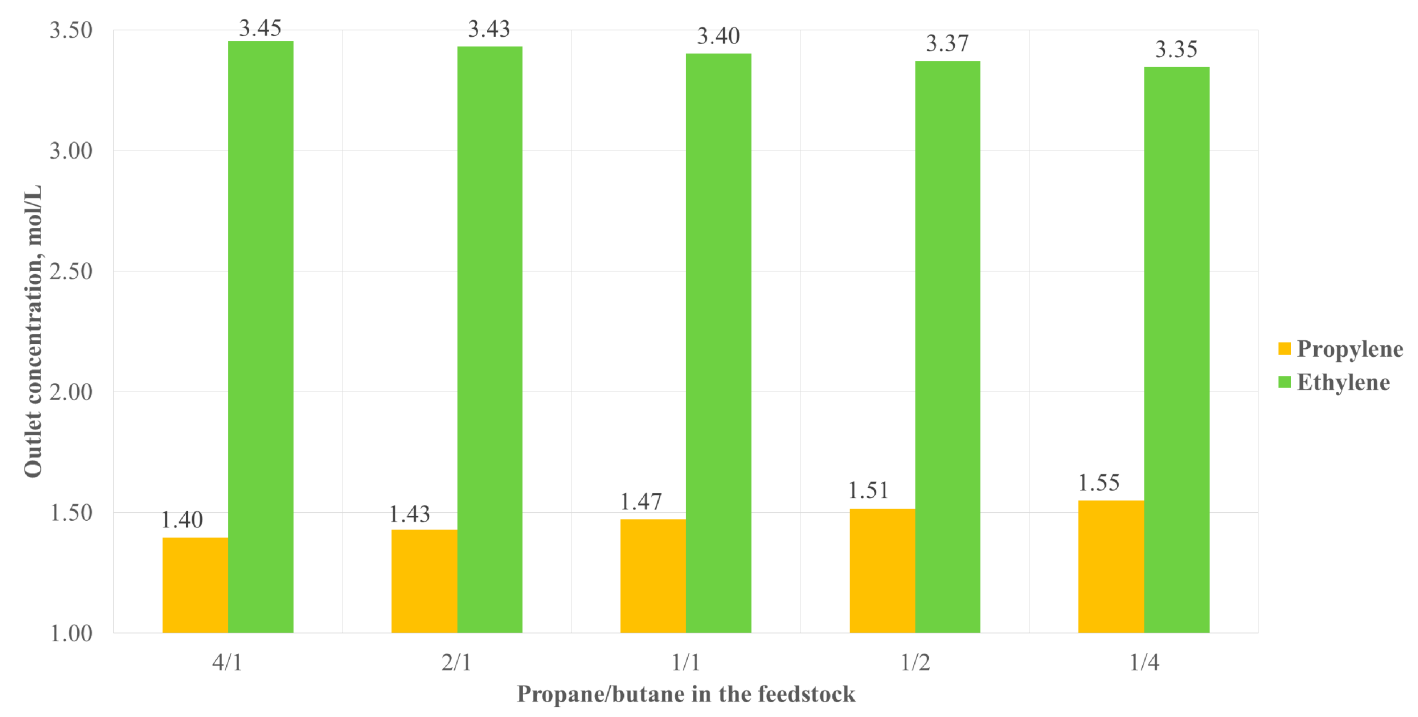

Figure 9. Influence of propane/butane ratio in the feedstock on the yield of propylene and ethylene.

With an increase in the propane/butane ratio from $4 / 1$ to $1 / 4 \mathrm{~mol} / \mathrm{mol}$, the ethylene concentration decreased from $3.45 \mathrm{~mol} / \mathrm{L}$ to $3.35 \mathrm{~mol} / \mathrm{L}$. Therefore, it is necessary to regulate the composition of the supplied feedstock to obtain the appropriate products in the required quantities.

\section{Conclusions}

The presented research yielded a number of important results:

(1) The unsteady-state mathematical modeling of hydrocarbon feedstock pyrolysis was developed. It considers the process of coke deposition along the length of the coil showing that the thickness of the coke layer increases towards the end of the coil. This proves the uneven distribution of coke inside the coil, which is consistent with theoretical concepts of coke deposition processes.

(2) The rates of coke deposition along the length of the coil were determined, considering the technological parameters and the composition of the supplied raw materials (the calculated value of coke deposition rate equaled $0.01 \mathrm{~mm} /$ day).

(3) The influence of the propane/butane ratio in the feedstock on the quality of the products was determined. With an increase in the propane/butane ratio from $4 / 1$ to $1 / 4 \mathrm{~mol} / \mathrm{mol}$, the ethylene concentration decreased from $3.45 \mathrm{~mol} / \mathrm{L}$ to $3.35 \mathrm{~mol} / \mathrm{L}$.

In future work there is a plan to increase the number of components involved in the reaction network to develop mechanisms that simulate the dynamics of the components in real time. This will make the model completely unsteady. There is also a plan to introduce the heat transfer equation into the general system of differential equations, taking into account the rate of heat transfer through the contaminated wall, thereby considering the uneven heating of the flow. In addition, there is as plan to add equations for changing the pressure of the gas flow along the length of the coil by increasing the hydraulic resistance. A model that predicts the state of the system and performs calculations based on the data accumulated for the entire production time is going to be developed.

Author Contributions: Conceptualization, I.D. (Irena Dolganova) and I.D. (Igor Dolganov); software, A.B.; data analysis: I.D. (Igor Dolganov), A.B.; writing-review and editing, I.D. (Irena Dolganova). All authors have read and agreed to the published version of the manuscript.

Funding: This research was funded by Russian State Project "Science" FSWW-2020-0011. 
Acknowledgments: The research was supported by Tomsk Polytechnic University within the framework of the Tomsk Polytechnic University Competitiveness Enhancement Program and Russian State Project "Science" FSWW-2020-0011.

Conflicts of Interest: The authors declare no conflict of interest.

\section{References}

1. Khasanov, R.G.; Murtazin, F.R. Prediction of Yields of Lower Olefins during Pyrolysis of Hydrocarbon Feedstock. Chem. Technol. Fuels Oils 2020, 56, 341-346. [CrossRef]

2. Boscagli, C.; Morgano, M.T.; Raffelt, K.; Leibold, H.; Grunwaldt, J.-D. Influence of feedstock, catalyst, pyrolysis and hydrotreatment temperature on the composition of upgraded oils from intermediate pyrolysis. Biomass- Bioenergy 2018, 116, 236-248. [CrossRef]

3. Zhang, L.; Wen, X.; Ma, Z.; Sha, X.; He, H.; Zeng, T.; Wang, Y.; Chen, J.; Zhang, L. Study on the NO removal efficiency of the lignite pyrolysis coke catalyst by selective catalytic oxidation method. PLoS ONE 2017, 12, e0182424. [CrossRef] [PubMed]

4. Li, X.; Shen, B.; Guo, Q.; Gao, J. Effects of large pore zeolite additions in the catalytic pyrolysis catalyst on the light olefins production. Catal. Today 2007, 125, 270-277. [CrossRef]

5. Bhoi, P.; Ouedraogo, A.; Soloiu, V.; Quirino, R. Recent advances on catalysts for improving hydrocarbon compounds in bio-oil of biomass catalytic pyrolysis. Renew. Sustain. Energy Rev. 2020, 121, 109676. [CrossRef]

6. Zou, R.; Lou, Q.; Liu, H.; Niu, F. Investigation of coke deposition during the pyrolysis of hydrocarbon. Ind. Eng. Chem. Res. 1987, 26, 2528-2532. [CrossRef]

7. Rahman, M.; Chai, M.; Sarker, M.; Nishu; Liu, R. Catalytic pyrolysis of pinewood over ZSM-5 and CaO for aromatic hydrocarbon: Analytical Py-GC/MS study. J. Energy Inst. 2020, 93, 425-435. [CrossRef]

8. Ratnasari, D.K.; Nahil, M.A.; Williams, P.T. Catalytic pyrolysis of waste plastics using staged catalysis for production of gasoline range hydrocarbon oils. J. Anal. Appl. Pyrolysis 2017, 124, 631-637. [CrossRef]

9. Fau, G.; Gascoin, N.; Steelant, J. Hydrocarbon pyrolysis with a methane focus: A review on the catalytic effect and the coke production. J. Anal. Appl. Pyrolysis 2014, 108,1-11. [CrossRef]

10. Gong, K.; Cao, Y.; Feng, Y.; Liu, S.; Qin, J. Influence of secondary reactions on heat transfer process during pyrolysis of hydrocarbon fuel under supercritical conditions. Appl. Therm. Eng. 2019, 159, 113912. [CrossRef]

11. Jing, X.; Zhao, Y.; Wen, H.; Xu, Z. High Olefin Yield in Pyrolysis of Heavier Hydrocarbon Liquids Using Microwave as Heat Supplier. Energy Fuels 2017, 31, 2052-2062. [CrossRef]

12. Gebreslassie, B.H.; Slivinsky, M.; Wang, B.; You, F. Life cycle optimization for sustainable design and operations of hydrocarbon biorefinery via fast pyrolysis, hydrotreating and hydrocracking. Comput. Chem. Eng. 2013, 50, 71-91. [CrossRef]

13. Pinkowski, N.H.; Ding, Y.; Johnson, S.E.; Wang, Y.; Parise, T.C.; Davidson, D.F.; Hanson, R.K. A multi-wavelength speciation framework for high-temperature hydrocarbon pyrolysis. J. Quant. Spectrosc. Radiat. Transf. 2019, 225, 180-205. [CrossRef]

14. Li, Z.; Wang, H.; Jing, K.; Wang, L.; Li, Y.; Zhang, X.; Liu, G. Kinetics and modeling of supercritical pyrolysis of endothermic hydrocarbon fuels in regenerative cooling channels. Chem. Eng. Sci. 2019, 207, 202-214. [CrossRef]

15. Feng, Y.; Jiang, Y.; Li, X.; Zhang, S.; Qin, J.; Cao, Y.; Huang, H. Numerical study on the influences of heat and mass transfers on the pyrolysis of hydrocarbon fuel in mini-channel. Appl. Therm. Eng. 2017, 119, 650-658. [CrossRef]

16. Savage, P.E. Mechanisms and kinetics models for hydrocarbon pyrolysis. J. Anal. Appl. Pyrolysis 2000, 54, 109-126. [CrossRef]

17. Samedov, F.A.; Morozov, A.Y.; Samoylov, N.; Prosochkina, T.R. Mathematical Modeling of the Unsteady Hydrocarbon Pyrolysis Process. Pet. Chem. 2019, 59, 151-159. [CrossRef]

18. Dolganova, I.; Dolganov, I.; Ivanchina, E.; Ivashkina, E. Alkylaromatics in Detergents Manufacture: Modeling and Optimizing Linear Alkylbenzene Sulfonation. J. Surfactants Deterg. 2018, 21, 175-184. [CrossRef]

19. Dolganova, I.; Ivanchina, E.; Dolganov, I.; Ivashkina, E.; Solopova, A. Modeling the multistage process of the linear alkylbenzene sulfonic acid manufacturing. Chem. Eng. Res. Des. 2019, 147, 510-519. [CrossRef]

20. Ivanchina, E.D.; Ivashkina, E.N.; Dolganova, I.O.; Belinskaya, N.S. Mathematical modeling of multicomponent catalytic processes of petroleum refining and petrochemistry. Rev. Chem. Eng. 2019. [CrossRef] 
21. Chuzlov, V.; Nazarova, G.; Ivanchina, E.; Ivashkina, E.; Dolganova, I.O.; Solopova, A. Increasing the economic efficiency of gasoline production: Reducing the quality giveaway and simulation of catalytic cracking and compounding. Fuel Process. Technol. 2019, 196, 106139. [CrossRef]

22. Zhorov, Y.M. Modeling Physicochemical Processes of Petroleum Refining and Petroleum; Chemistry: Moscow, Russia, 1978; p. 376. (In Russian)

Publisher's Note: MDPI stays neutral with regard to jurisdictional claims in published maps and institutional affiliations.

(C) 2020 by the authors. Licensee MDPI, Basel, Switzerland. This article is an open access article distributed under the terms and conditions of the Creative Commons Attribution (CC BY) license (http://creativecommons.org/licenses/by/4.0/). 